\title{
微量元素在植物中的生理作用及其 在农業实踐上的意义
}

崔澂

(中国科学院北京植物生理研究室 南开大学)

\section{引寻}

植物在正常生命活动中需要節多元素。早在 1851 年 Salm-Horstman ${ }^{[1]}$ 已經采用沙基培养的方法, 酒:

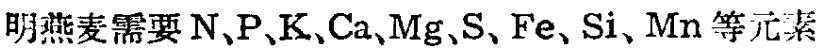
才能生长正常。1860年 Sachs ${ }^{[2]}$ 及 Knop[3] 文分別 用溶液培养的方法研究了植物需要的元素, 他們的結

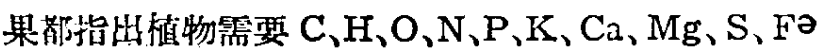
等十种元素。鉓对㨁物的需要性是被 Raulin ${ }^{[4]}(1869)$ 用道落証明的, 1910 年Agulhon ${ }^{[5]}$ 又証明硼对高等植 物是一个很有好处的元素; Bortels[ $[$ [1927) 登現鉄、 錇、銅可以促进微生物的生长，他[7]又在 1930 年研究

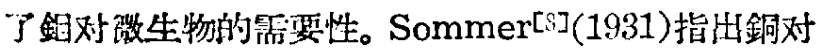
离等匆物的生长也是必需的。后来 Stout 和Arnon [ $[9]$ (1939）用精细的培养方法研究了十几种微量元素对高 等植物生长的必需性, 他們的絬果泟明 $\mathrm{Zn} 、 \mathrm{Mn} 、 \mathrm{Cu}$ 、 B、Mo 五种元素都是高等植物所必需的, 还有些元 素如 $\mathrm{Ti} 、 \mathrm{~V} 、 \mathrm{Cr} 、 \mathrm{~W} 、 \mathrm{Co} 、 \mathrm{Ni}$ 的存在对倠物的生长也略 有好处。現在已經十分肯定至少有 $C 、 H 、 O 、 N 、 P 、 K 、$ $\mathrm{Ca} 、 \mathrm{Mg} 、 \mathrm{~S} 、 \mathrm{Fe} 、 \mathrm{Mn} 、 \mathrm{Cu} 、 \mathrm{Zn} 、 \mathrm{~B} 、 \mathrm{Mo}$ 十五种元素是枯 物生活所必需的。至于必需元素的定义, Arnon[10] (1953) 認为应当具有以下三种条件:（1）缺乏必需元 素植物不能正常生活和不能完成其生活史; (2) 必需 元素对植物生活具有一筀的生理作用而不能为其他元 素所代替; (3) 必需元素对植物有直接的作用, 包括 代謝过程。最近的研究, 某些必需元素的不同代替性 是相对的而不是絕对的。还有不少研究祉明有些元素 像 $\mathrm{Cl} 、 \mathrm{Si} 、 \mathrm{Al}$ 和天然放射性元素 $\mathrm{Ra} 、 \mathrm{U}$ 等对植物的生 长和㓎育也有好处, 这些元素一般称有谷性元素。我 們应該着重指出的是現在所謂那些元素是必需元素, 那些是有益元素, 只是在目前的科学水平上說的。按 照 Вернадский[11] (1922) 的意見, 在地球上生命現 象中起特殊作用的, 不仅有大量元素, 而且有徽量元 桌和超微量元素。这三类元素的区別是什么呢? 主要 是根据元素的需要量而区分的, 植物需要量較多的元

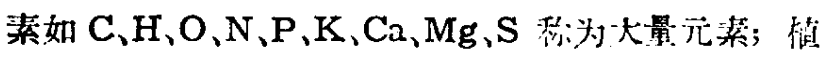

物需要墔較少的元素如 $\mathrm{Fe} 、 \mathrm{Mn} 、 \mathrm{Zn} 、 \mathrm{Cu} 、 \mathrm{~B} 、 \mathrm{Mo}$ 秒为

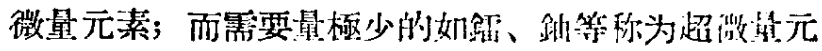
素。

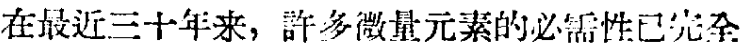
証实, 对它佂的生理作朋也是开了广泛的研党, 由于 物理、化学以及生物化学的触很, 对这方面的工作起

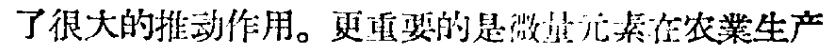

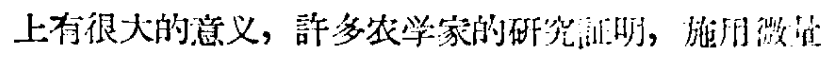

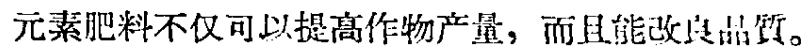
苏联的农業工作者在不同上嫂里施朋湖，銅等潵量元 素肥料，对亚䟽、甜荣、行类作物的产量能大大地提 高; 美国在果林截培方面利用鉝肥也得到很好的效果。 我国最近十几年来也在溦量元素方面做了一些研究工 作。1940 年以后，罗宗洛等不始研究微占元卖的生理 作用，他[12]在 1947 年做了总䋨䞍的报占。1942年:

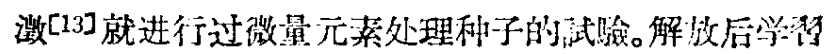
了荕联在这方面的成就，对微冒元素的研究工作文推 动了一步。

\section{研究徽量元素必需性的方法}

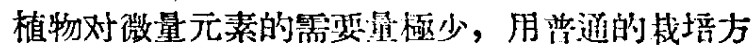
法就無法泟明它的必需性, 即便用溶液培养, 如果港 餾水和萂剂不純，培养器皿質量不好，也很难得到正 确的結果。因此研究 $\mathrm{Zn} 、 \mathrm{Mn} 、 \mathrm{Cu} 、 \mathrm{Mo}$ 等微量元素, 常 用硬質玻琌制的培养器(欧美用 Pyrex 等), 研究硼

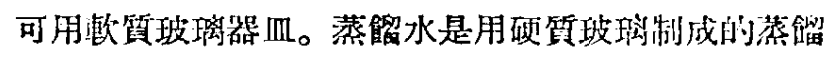

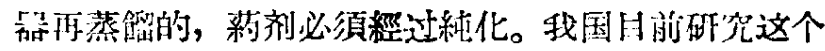

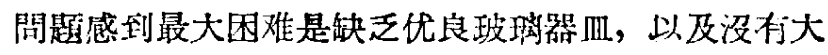
量質量好的再蒸㙁水。我們为了在现有的条作下让行 微量元素的研究工作, 自 1955 年开始了培器力沙的研 究工作，抹获得成功(圖 1)。玻琌器最好的是过去中 央（現名中元）玻琌厂的产品，水是用普掘蒸柃水經 过碳酸釷純化处理，䒬剂的純化仍尔用 Stout 和 Arnon ${ }^{[0]}(1939)$ 的方法。

至于研究微量元素的生理作用以及农業实踐上如 何应用的問題，可根据目的采取冬和不同的方法，例 


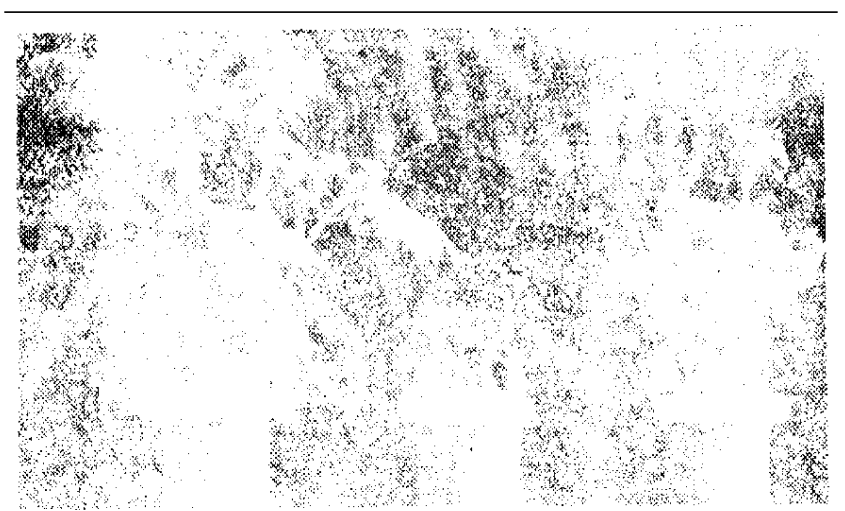

国 1 左 芫全培染液中的对照植物

中 触鋅的植物;

右 植物加鉝后棸恢复生长。

如田間試驗, 土培培养, 砂基培养, 溶液培养, 种子 处理, 根外施肥等均可。

\section{微量元秦的生理作用}

研究微量元素的生理作用首先是不能忽悓历史的 方法, 过去有些学者認为微量元素是剌激妻、兴奋剂、 或接触剂的看法显然是不够全面的。俄国地質化学家 Вернадский[11] 用历史的覌点研究了微量元秦的問 题, 他認为, 生物的化学成似是与地壳构造互相連系 的, 这也就是生物与环境的統一，植物在万史發育过 程里形成了它对研質营养需要上的特性。此外，还必 須应用物理的和化学的方法把微量元素对植物的个别 生理过程以及各个生理过程之閵互相关系的作用加以 分析。

生物有机体是由原生質构成的，原生質是复杂的 胶体，其中含着有机物質、無机物質和水。主要的有 机物質是蛋白質、碳水化合物、脂肪、有机酸、維生 素、激素和酶等; 而主要的無机物則是許多矿翼元素， 例如 $\mathrm{K} 、 \mathrm{Ca} 、 \mathrm{Mg}$ 等。以上这些物質和水构成了一个复 杂的动态系統，代謝作用就是这个系統的具体表現。 各种物質在系統中都是互相联系着的, 有的比較泌切, 有的比較䟽远，微量元素在整个系統中起着不可缺少 的作用。

有机体的原生管是一个复杂的胶体，而微量元素 对原生賈胶体的物理、化学性質有很大的影响，这些 性質的改变对新陈代謝过程有復切关系。Окуннцов[14] (1950)指出，銅对叶綵体的胶体系統有稳定的作用; Школьник[15]（1950）报告矹、銛、锌、銅、鋁等提 高了植物在干旱时自由水和結 合水的含量; Новицкая[16](1955)的研究，泟明硼、鎾、铜、锌可以增加 植物的結合水; 崔激和桂美祘 ${ }^{[17]}$ (1957)最近的实驗, 用硫酸銅处理棉花种子，胁苗的保水力及蒸腓作用都 有所提高。微量元素影响原生質胶体的改变, 还可以 场加植物的抗旱和抗寒能力: Школьник[15] 等(1950)
發現明、鎾、锌、銅、鉊等对提高份物的抗早力很有 好处; Окунніов ${ }^{[18]}$ (1952) 报告磁、鲜能提高值物 的抗寒性。

酶的研究是現代生物化学的重要貢献之一，醮在 代謝过程中起着关鍵性的調剂作用。徽量元素与酶的 关系, 近几年来有很多研究, 可以从两个方面来說明。 一方面有些微量元素就是酶的成分, 例如在椺物的等 化还原过程中起重要作用的多酚氧化醇、抗坏血酸等 化酶中都含有銅; 在动物的呼吸系統中起决定性作用 抹集中在紅血球中的碳酸酮酶就含有鋅; 近来在林 物体內也狆現有此酶存在, 筆且集中在叶綠体內, 但是它在植物体內起的作用有待于进一步的研究。 Nicolas[19](1954) 不久以前証明大亘的硝酸还原酶中 有銆, 由于鎮的存在而大大地加速了硝酸的还原。此 外，大家早已知道鉄是过氧化物酶、过氧化氞酶和細胞 色素 $\mathrm{C}$ 的成分。Nason 等[ ${ }^{[0]}$ 报告当蕃茄植物缺之微 量元素时，則使含有关金屬的酶的活动性大大地降低。 另一方面微量元素是很多酶的活化者, 現已証明很多 酶都可以受微量元素的活化。Sadasivan[21](1950)用 Pencillum chryrogenum 为材料, 証明鋅对磷酸酶有 活化作用,他認为这种酶可能含有鋅。Najjar [22](1951)

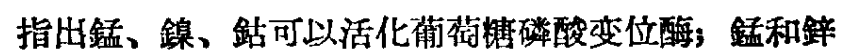
可以活化烯醇化酶; 鋅可以活化多胜酶。崔激和赵素 娥 [23](1957) 最近的研究, 認为 $\mathrm{Zn} 、 \mathrm{Mn} 、 \mathrm{Cu}$ 和 Mo 对 水稻幼苗中过氧化物酶的活性有促进作用。崔激和哭 兆明[24] (1957) 㺕現在缺鋅的蕃茄植物中过氧化筑醀 的活性大大地降低，当培美液中加鋅以后，这种酶的活 性就逐漸诙复（圖 2)。但是 Nason 等[20]墢現在缺錇 等微量元素的蕃茄植物中，多酚氧化酶和过氧化物酶 的活动性反而堵加了。由此可知微量元素和酶的关系 是十分复杂的。

光合作用是綠色植物制造有机物質的基本过程， 微量元素在这一生理过程中也起着一定的作用。Ger一

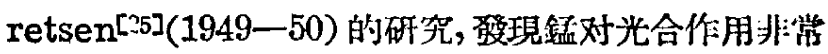
重要; Скворцов ${ }^{[26]}(1950)$ 得到相同的結果。OкунLOB [27](1950) 指出銅有稳定叶綠素的作用, 可以防止 叶綠素的破坏。同时我們知道叶子內的銅几乎全部集 中在叶緣体內。最近 Бойченко[28]等(1954)研究鉄在 光合作用中的作用得到很有趣的結果，他們用 $60 \%$ 的 丙酮从質体內得到的制备物可以提高 $\mathrm{CO}_{2}$ 的同化 5 倍 以上，其中含有鉄，这种制备在沒有叶綠体的情况下 也能固定 $\mathrm{CO}_{2}$, 这一發現对进一步研究人工光合作用 有很大的啓磁。

呼吸作用是表示生活过程的总指标，在微量穴素 和呼吸作用的关系方面，1939 年 Lundegardn ${ }^{[99]}$ 就 曾指出銛有促进呼吸作用的事实。但是准激 ${ }^{[20](1948)}$ 


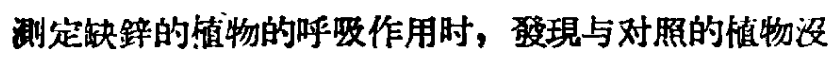
有明显的差开。最近崔激和赵素娥 ${ }^{[23]}$ (1957) 用微量 元素处理水稻种子，測定它們对生长及呼吸作用的影 响。他們喥現 $\mathrm{Cu} 、 \mathrm{Mn} 、 \mathrm{Zn} 、 \mathrm{Mo}$ 等微量元素对生长和 呼吸都有不同程度的促进作用。鋅对根的生长有显著 的好处, 但对蕉来喰, 任何涱度都有抑制作用, 同时 他储看到微量元素对生长和呼吸的作用有一定的关 系, 一般在較低的瀑度时促进生长就促进呼吸, 但在 交离的港度时, 生长仍然比对照好, 可是呼吸作用已 柾受到抑制了。崔败和赵素娥[23]还研究了微量元素对 呼吸抑制剂的作用，他們曾研究用楀化鈵、碘碏酸、

系化鉀、丙二被等微量元素处理种子后对水稻幼苗呼 吸作用的影响, 結果証明凡用 $\mathrm{Cu} 、 \mathrm{Mo} 、 \mathrm{Mn} 、 \mathrm{Zn}$ 处理 者都在不同程度上克服了化鉡、碘醋酸的抑制作用, 对無化鉡的作用尤为显著 (圖 3 )。可能由于这些元素 和奥化鉡結合为絡合物，使奥化鉡失去了抑制呼吸的 作用。

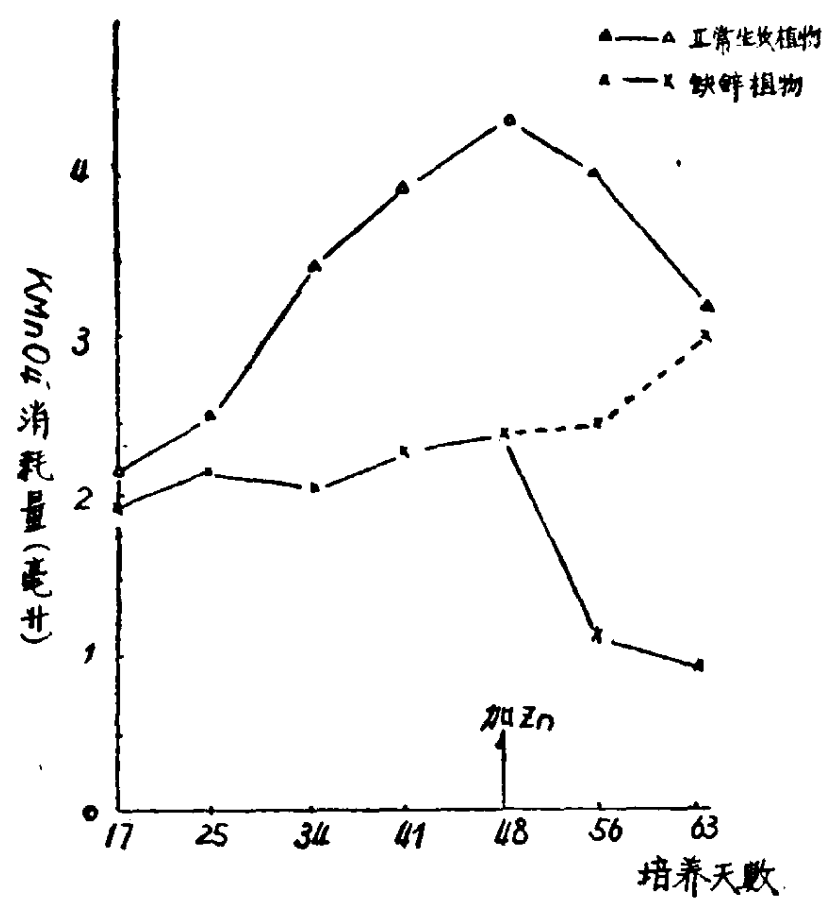

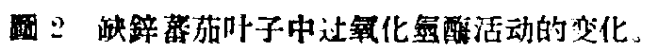

代謝过程的两个主要 5 面是物質的合成和分解， 微量元素和这个过程也有密切关系。Школьник[31] (1939) 早就指出嗍可以影响蛋白缶的合成，㮛据 Окунцов ${ }^{[18](1952)}$ 的报告, 銅也有同样的作用。Ocтровская 等[32] (1955) 把有 $\mathrm{N}^{15}$ 的盐供給正常及缺銅 的植物, 他們發現在正常植物的叶子里有更多的 $\mathrm{N}^{15}$ 。 Spencer 和 Wood[33] (1954) 指出錩对氮素同化作 用有影响。鋅和氮素同化作用的关系地有很多研究。 Bean ${ }^{[34](1942)}$ 指出，番茄植物缺鋅时抑制了蛋白貿 的合成。准激 ${ }^{[35]}$ (1948) 酸現蚗鋅的植物色氮酸的含 很少。Chester[36]等(1950)报告 Neurospora 蛜鋅
时不能利用吲棎和絲氨酸合成色氛酸。

微量元妻与植物生长素的关系也有很多人研究 过, Skoog[37] (1940) 撥現在缺鋅的植物里生长素的 合量显著减少，他認为是由于氧化酶的活动加强，把 生长素破坏了。但崔激[35]的研究証明, 生长素的减少 是由于生长素前身一色氮酸的形成受了抑制。最近 崔激和哭兆明[24] (1957) 測定了缺鋅植物中过氧化敛 酶的活动，它是因缺鋅而降低了(圆 2)。锌与生长素 的关系是十分密切的, 崔激[38]的研究, 鎬在植物里的 分布与生长素的分布是平行的, 在生长胿盛的祁位, 生长素的会量很多，同时鎊也很多。

此外, 在代謝作用上溦量元素还可以影响碳水化 合物、橡抆、維生素的含量。罗宗洛和倪習山[ [39](1945)

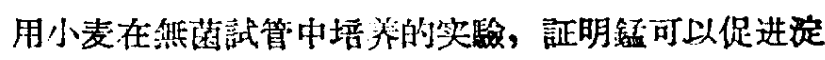
粉的分解。金成忠 ${ }^{[40](1947)}$ 又进一步研究了錳对小麦

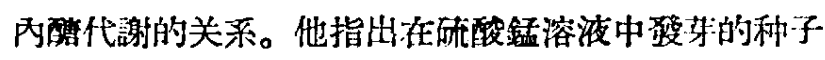

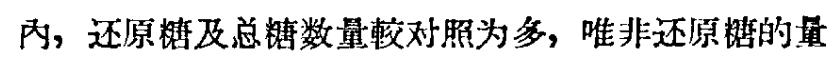
則較对照为少。罗宗洛等[41] (1947) 用硫酸敘、硫酸

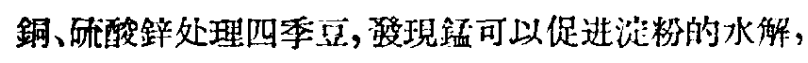
硫酸銅对于淀粉分解的影响不如舒之优主。研酸鋅处 理后，淀粉及非还原糖的量較对照为多，唯还原糖的 量則較对照为少。

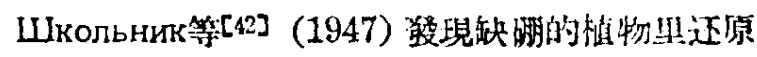
㜍及腚粉的含量减少。最近的研究証明, 硼可以和碳 水化合物等形成絡合物。Скворцов[43] (1950) 报告了 錳可以提高燕麦碳水化合物的间化作:用。Gauch [14]

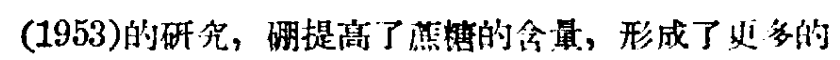
可以轉䔟的碳水化合物。

微量元素对植物生长和發育的影响, 訢多人 $[13$.

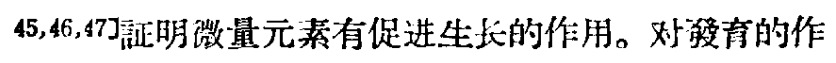
用是近来才研究的。Школьник ${ }^{[48]}$ (1940)卓就指计明

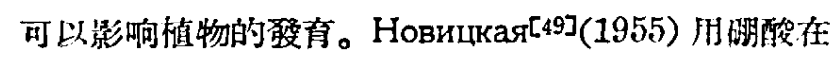
播种前处理玉米种子, 結果当对照有 $14.2 \%$ 抽穗时处 理者已有 100\%。山кольник 和 Стекנюва[50](1955) 前后泟明硼、钿、磷对冬小麦通过春化阶段住很大的 作用。崔激和王保重 ${ }^{[51]}(1957)$ 的实驗, 用三种冬小麦

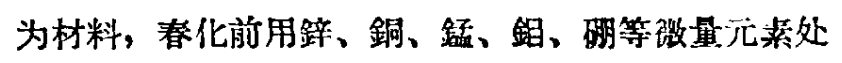
理, 除楥过鎾和鉄处理反而抑制了春化阶段外: 其他元 素对三个品种通过春化阶段均有促进的作用（楒4)。 这一發現对进一步研究鎾的生理作用以及春化阶段的 本犋都有很大的意义。关于微量元素促进了春化的解

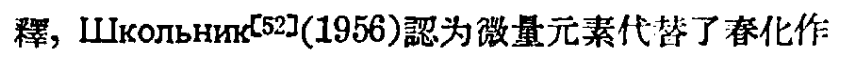
用，我的意見是徽量元素加速或延楥了通过春化阶段 的过程。

还有很多資料㗏明微量元素与性的分化任关， Kühnn ${ }^{[53]}$ (1943) 提供有趣的实驗, 他証明用嗍处理 
Chlamydomonas 米分化的抱子，可以得到雄性的狍 子。罗宗洛和黄宗甄 ${ }^{[54]}$ (1944)的研究, 錳可以促进花 粉管的伸长。

从上面的事实可以看出，微量元素对植物的作用 几乎涉及到一切生理过程。但这样不能就說微量元素 的作用相同，也不能說微量元素的作用是多方面的。 因为生命活动有非常复杂的机制，它是由許多不同的 生理过程联系起来, 相互之間有密切的关系, 也可以

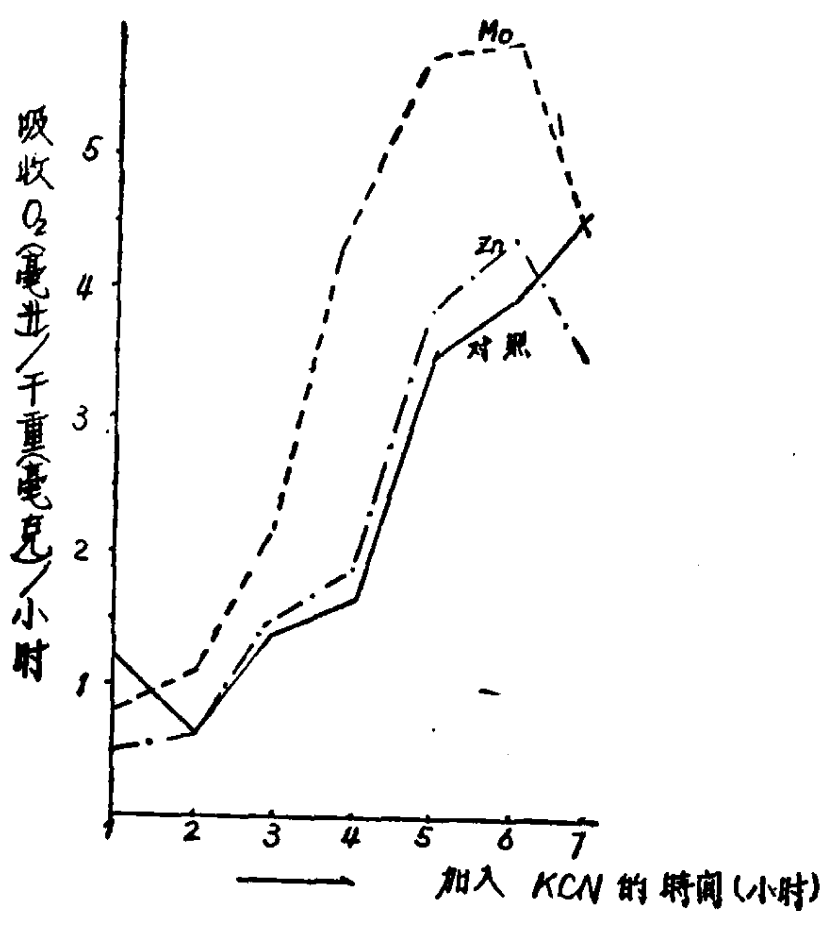

橉 3 微量元素处理种子对呼吸抑制剂的作用 (用 Zn 100 p. p, m., Mo 50 p. p. m. 浸种 24 小时)

說是許多矛盾方面的統一过程。一种微量元素可能对 其中一个过程或几个过程起作用, 也許只对一个过程 的某一环节起作用。生理过程既然是相互联系的, 它 破很可能比較間接地影响其他的一些过程。由于我們 現在对有机体的生理、生化的知識还很少, 所以就很 难确定微量元素最直接的生理作用。虽然如此，我們 对几种必需的改量元素的生理作用也有了一定的了 解，例如，銅、鉄是許多等化酶的成份，钼是硝酸还 原酶的成份，可以影响食素同化作用。磁是碳醏酶 的成份, 它与生长素的施身一色氨酸的形成有密切 关系。

最后还必須指出，各种微量元素的生理作用不是 孤立的，也不是絕对不可代替的，現在已有很多資料 証明銛和鉄在植物体內有一定的相关性, 鎾可以部分 地代替鉄。Школьник ${ }^{[55](1955)}$ 还指出缺矹时加 $\mathrm{H}_{2} \mathrm{O}_{2}$ 可以代替, 但也不能因此而否定了每个微量元素的特 殊作用。

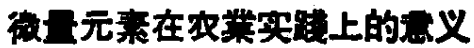

从上面我們知道微量元素有很重要的生理作用, 缺乏时就使植物生长不正常。农数的目的是要作物多 生产我們生活上需要的东西, 为了保証能得到这些产 品, 首先要使作物生长良好, 而微量元素在这方面是 不可缺少的条件之一。在研究微量元素在农業实践上 的意义时，我們必須注意以下几个問題。第一是地区 性。在不同地区的不同土壤中微量元素的含量是不一 样的, 根据 А. П. Виноградов ${ }^{[56]}$ (1940)的研究，土 壤中微量元素的含量决定于母質、植被、士壊熟化的 程度，以及从外部施入的数量。在酸性岩石發育成的 酸性灰化土中就特別缺乏錩和跍。在基性岩石所形成 的土壤中，錩、鈷的含量就很多。例如苏联的非黑䥄土 的地带缺之矹，而泥炭土缺之銅。美国的加里佛尼亚、 佛罗里达的土靖就缺鋅，因此在农業生产上应用微立 元素絕对不能硬搬其他地区的結果。第二是作物的特 性。各种作物对微量元素的需要也不一样, 禾本科作 物对矹的需要就不如亚湖和甜茶。准激和桂美祥[17 (1947)証明不同品种的棉花对銅的反应就不同。所以 农業上施用微量元素时还必需注意作物的品种和性 筫。第三是其他条件的影响。光度、土壤酸碱度等都 可以影响微量元素的作用。例如土壇酸碱度宿时, 土

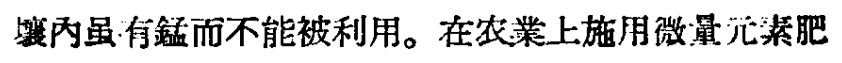
料的方法主要有三种, 肥料的种类因方法而异。(1) 在土壤里施溦量元素肥料: 矹酸、矹砂、矹鉃泾漳可

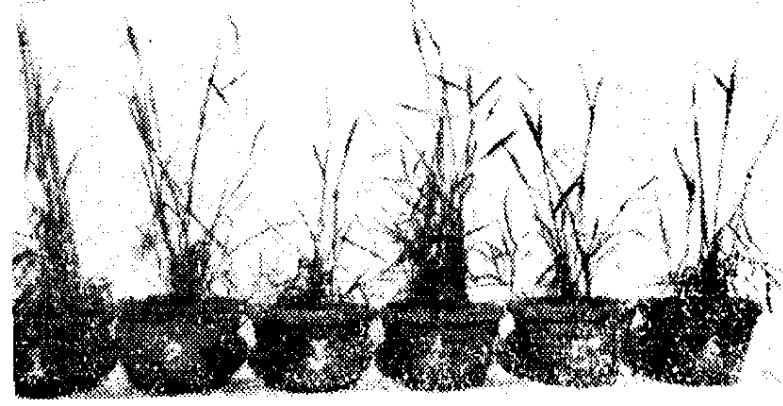

D 4 数量元素对冬小麦管化阶段的影响

(品种: 远化: 35 天)

1. $\mathrm{Cu} ; 2 . \mathrm{Zn} ; 3 . \mathrm{Mn} ; 4 . \mathrm{Mo} ; 5 . \mathrm{B} ; 6$. 对照

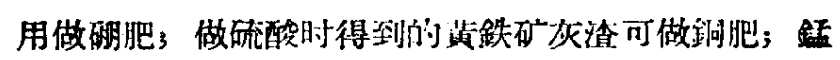
鉄矿渣可做錳肥。(2) 根外斿肥: 因为植物对微量元 素的需要量極少, 采用噴施的方法既方便又經济, 也 很有效, 凡是水溶性的微量元素的盐或酸均可应用。

（3）种子处理: 为了使种子萌郋、幼苗生长以及后期 生长良好, 常用微量元素的溶液浸种, 这种方法簡易 可行, 持有一定的效果。究竟采用那种方法可根据等 件及目的而定。

微量元素在农業生产上的澺义是务方面的，数据 
很多，它的作用与地区及作物特性有关，多介紹也沼有 必要, 現至只重点地引証一些研究結果。微量元素对 許多特用作物的增产有很好的效果，其中最突诎的是

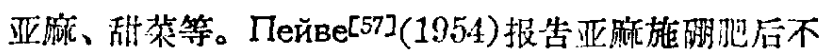
仅提高了維維的产量和长度，而且提早开花 8-10天。 A. В. Носкова[58](1934)的研究，在施石灰后的土境 中加錳，对亚施生长有良好作用，瀻維的影性和长短 樴維的比数鄚增加了。Пейве[57](1954)报告在 “劳动 的旗帜”棐体农庄施銅后，亚麻种子增产 90 公斤/公 頃，饿維㙕产 65 公斤/公頃。白俄罗斯社会主义共和

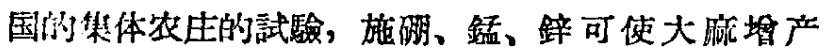
10-13\%。微量元素对甜茶的效果也很好，嗍不但可 以提高产量, 而且能改良品質。Власюк ${ }^{[59]}$ (1939) 研 究施錳矿廢弃物时, 可以增加甜㭉的产量 11-12\%。

微量元素对禾谷类作物提高产量的效果及实例也 很好, 它們对朋的缺乏不像亚麻、甜荣那么敏感，可 是其他微量元素在禾谷类的生产上仍有很大的意义。 白俄罗斯共和国沼澤土上施用銅肥可使小麦、燕麦、 大麦每公頃增产 6-12 公坦。9. М. Лагановский[0] （1952）用 0.4\%硫酸踥溶液噴射作物，黑麦垭产 14.7 $40.9 \%$, 燕麦增产 9.4-25.5\%，春小麦增产 $12.5-$ 14.4\%。王象坤等[61](1956)用微量元素浚波处理小 麦、水稻种子及根外䨢施，在某些实驗中也获得增产 的效果。林業士壤研究所朱洪 ${ }^{[62]}$ 用微量元素噴大豆, 不仅坦加了产量，而且提高了含油率。

㳂荣也可因施微量元素而罾加产量, Катальмов [63](1952) 的研究，施朋肥提高了甜荣、甘㤵的产量。 BласюK ${ }^{[64]}$ (1952)报告施錳肥使馬鈴著每公比增产 60 公坦，黃瓜增产 40.5 公担，番茄增产 36 公担，甘藍增 产 50 公担。М. В. Катальмов[63](1952) 指出鋅可以 提问踠豆、荣豆、大蒜的产量。В.С. '”хангельская 等[r5](1952)的研究, 在砂土施銅肥使馬鈴蓉塊䓠坦产 18\%。李家倬[66]等(1955)对番茄噴施微量元素，提高 了豆量和改进了品質。

微量元素的缺乏也可以影响果实的产舅以及树木

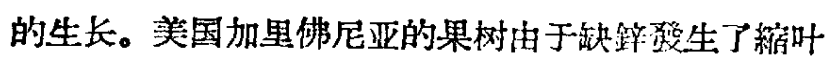
病，佛罗里达的泊桐树及美洲胡桃也因蚛鎊而生K不 良。

在植物保护方湎，微量元素也有很大的作用。 И. Е. Лукьяненко[67](1951)的研究, $\mathrm{B} 、 \mathrm{Mn} 、 \mathrm{Cu}$ 能 大大地提高春小麦对坚腥黑穂病的抵抗力: 施湖减少 染病率 $1 / 3-1 / 10 ;$ 施銅减少 $1 / 5-1 / 7$; 施全篮减少 $1 / 3-1 / 5$ 。 T. Д. Страхов[68工等 (1952)在田閏的实驗, 硫酸鋅使

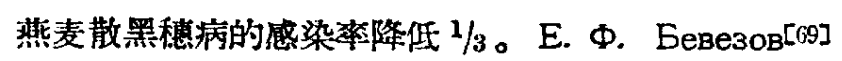
$(1939,1941)$ 报告亚麻缺嗍时引起了細菌性的病害, 这种病原菌类似 Bac, mrevans。我室研究生干保重
用嗍酸处理黄瓜种子，墢現对照考古部死亡，处理者 死亡較少，可惜病名未能監往。

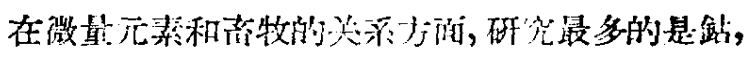

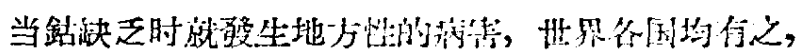

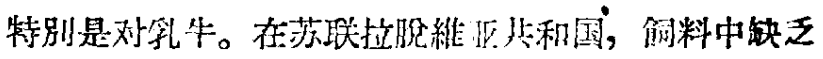

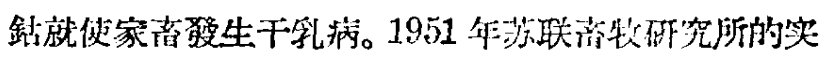

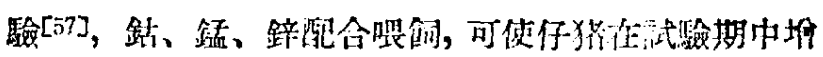

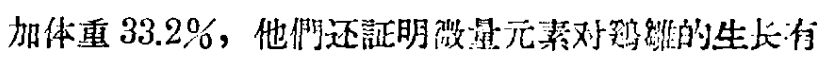
很好的作用。在新西兰 Cawthron 研究所对涻与语 牧的关䒺有很多研究。美国缄斯麻深 Geyer[70]等

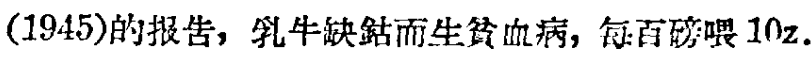
$\mathrm{CoSO}_{4} \cdot 7 \mathrm{H}_{2} \mathrm{O}$ 即可沙除。

从上面这些結果知道微量元絜在农澲生产，上如如 何的重要，可以說与一切农業生产都有关系。这方面 的工作在我国几乎是空白。

\section{对我国开展徽量元素研究工作的量見}

根据国务院制定的科学远景兒划，很洺工作: 都涉 及到微量元素的問題, 总起来說有两力面工作: (1) 理論上要研究它們的生理作用，(2) 生产.1婹研究它

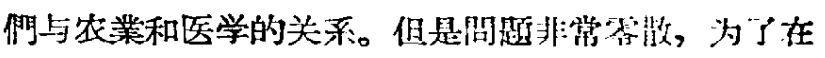
微量元素研究已有的基础上很快地赶上国际水平，溜 該組織全国有关力量, 从以下几个方面展开研究工 作:

1. 調查全国各地士墥微量元素的含量。

2. 研究我国各种主要士:襄类型中微量记素对: 注要 作物生长的影响。

3. 調查研究全国各地主装农作物、果树、治牧等 对微量元素的缺乏情况。

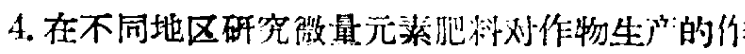
用。

5. 研究各种微量元素的必需性及其生理作用。 本交承中国科学院植物生理研究所罗宗洛所尤聿 閱, 特此玫㴬。

[1] F. Salm-Horstman, Ann. Chim. (Phys.) 32, 161 (1851).

[2] J. Von. Sachs, Landw. Verst Sta., 2, 219 (1860).

[3] W. Knop, Landw. Verst Sta., 2, 65, 270 (1860).

[4] J. Raulin, C. R. Acad. Sci. (Paris), 57, 228 (1869)

[5] H. Agulhon, Compt. Rend. Acad. Sci. (Paris), 151, No. 26 (1910).

[6] H. Bortels, Biochem. Z., 182, 301 (1927).

[7] H. Bortels, Arch. Mikrobiol., 1, 333 (1930).

[8] A. L. Sommer, Plant Physiol. 3, 217 (1931).

[9] P. R. Stout and D. I. Arnon, Amer. I. Bot., 26, 114 (1939).

[10] D. I. Arnon, Ed. Troug. Minenal Nutrition of Plants, Univ. Wis. Press (1953). 
[11] В. Вернадский, Изд. "Врөмя" (1922).

[12] 罗宗洺, 学艺杂志, 第17经, 第 4 号 (1947)。

[13] 崔 淮, 物学报, 第 3 管, 第 3 期 (1954).

[14] М. М. Окуниов и Н. М. Силева, “ученно зап. Томского Государственного Университета", 13 (1950).

[15] М. Я. Школьник, Значение микроэлемөнтов в Жизни Растөний и в Земледелий, Изд. АН СССР (1950).

[16] Ю. Е. Новицкая, СБ. “Микроялементы" Рига (1955).

[17] 桂美祥、崔数, 植物学报, 第 6 然, 第 1 期(1957)。

[18] М. М. Окунцов и О. П. Левцова, ДАН СССР 82, № 4 (1952).

[19] J. D. Nicholas and A. Nason, J. Biol. Chem., 207, 353, 211, 183 (1954).

[20] A. Nason, Henry A. Oldewurtel and Lois $M$ Propst, Arch. Biochem. and Biophysics, 38, 1-14 (1952).

[21] V. Sadasivan, Arch. Biochem. and Biophysics, 28, 100-110 (1950).

[22] A. Najjar, The Role of Metal Ions in Enzyme System, Phosphorus metabolism, I. Baltmore(1951).

[22] 崔 沙、赵素娥, 占末發表 (1957)。

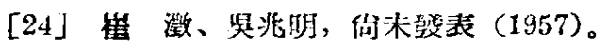

[25] F. C. Gerretsen, Plant and Soil, 1, No. 4, 346358 , 2, No. 2, No. 3, 323-342 (1949-50).

[26] С. С. Скворцов, Микроялементы в Сельском Хозяйстве и Мөдицине (1950).

[27] М. М. Окунцов, “Микроэлөмеңты в Жизни Растений и Животных", 371-380 (1950).

[28] Бойценко и В. И. Бараңов, ДАН СССР, 95, ㅌ 5 (1954).

[29] H. Lundegardh, Planta, 29, 3, 419-426 (1939).

[30] Tsui, C. (棺翼), Nature, 164, 970 (1948).

[31] М. Я. Школьник, Роль и Значение Бора и Других Микроэлементов в Жизни Растөний, Изд. AH CCCP (1939).

[32] Л. К. Островская и Г. М. Яковенко, СБ. “Микроэлөмөнты" Рига (1955).

[33] D. Spencer, and. J. G. Wood, Austral. J. Biol. Sci., 7, 425-435 (1954).

[34] R. S. Bean, Thesis for Ph. D. degree, Univ. of Calif (1942):

[35] Tsu, C. (俄激), Amer. J. Bot., 35, 172 (1948).

[36] G. G. Chesters and G. N. Rollinson, Nature, 165, 851 (1950).

[37] F. Skoog, Amer. J. Bot., 27, 931-951 (1940).

[38］崔 㴛, 植物学报, 第 3 学, 第 1 期, 31-36 (1954)。

[39] Loo T. L. (多宗洛) and Ni Tsin-shan (倪椐山), Sci. Rec., 1, 584-588 (1945).

[40] King Chien-chung (金成忠), Bot. Bull. Acad. Sinica, 1, 9-24 (1947).

[41] Loo T. L. (罗宗洛)等Bot. Bull. Acad. Sinica, 1,
213-220(1947).

[42] М. Я. Школьник, Н. А. Макарова ж. М. М. Стокпова, "Ботанический Журнал СССР" 32, 6, (1947).

[43] С. С. Скворцов, Рефораты Покл, на Конфор, по Микроэлем., Изд. АН СССР (1950).

[44] G. G. Gauch and W. M. Duggar, Plant Phisiol., 28, No. 3, 457-466(1953).

[45] Loo, T. L. (多宗洛) anp Tang Yu-wei (晹玉暲), Amer, J. Bot., 32, 106-114 (1945).

[46] 陆定志、然宗洛, 中国科学, 第 1 卷, 第 2-4 其, 379393 (1950).

[47] Tang Yu-wei (晹玉璄) and Yao-Yuan (姚媛)， Sci. Rec., 1, 223-229 (1942).

[48] М. Я. Школьник, В. К. Абашкин и М. П. Гринингер, “Экспериментальная Ботаника" 4, (1940).

[49] Ю. Е. Новицкая, “Микровлементы” Pига (1955).

[50] М. Я. Школьник и М. М. Стеклова, “Микроэпементы" Рига (1955).

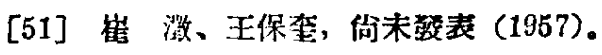

[52] М. Я. Школьник, “Микроэлементы в Сөльском Хозяйстве и Медицине", 227-245 (1956).

[53] R. Kühn, Wien. Chem. Ztg., 46 (1493).

[54] Loo T. L. (罗宗洛) and Hwang Tsung-chen (昔 宗甄), Amer. J. Bot., 31, 356-367 (1944).

[55] М. Я. Шкопьник и М. М. Стеклова, ДАН СССР, Серия Биологическая (1955).

[56] А. П. Виноградов, Микроэлөменты в Жизии Растений и Животных Изд.. АН СССР (1952).

[57] Я. В. Пайве, Микроэлементы в Сельском Хозяйстве Нөчернозөмной Полосы СССР, Изд. АН CCCP (1954).

[58] А. В. Носкова, Химиз. Соц. Землод., 8 (1934).

[59] П. А. Власюк, Изд. АН СССР (1939).

[60] Я. М. Лагановский, Автореф. Каңд. Десс (1952).

[61] 王象佣等, 椺物生理学通語, 第 6 号(1956)。

[62] 朱 淇, 植物学报, 第 5 焱, 第 4 期 (1956)。

[63] М. В. Катальмов, Тр. Конф. по Микровльментам, Кзд. АН СCCP (1952).

[64] П. А. Власюк, Изд. АН. СССР (1252).

[65] Н. С. Архакгөльская, Микроэльменты в Жиэни Растений и Животн19х, Изд. АН СССР (1952).

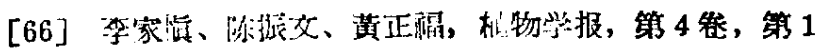
期 $(1355)$ 。

[67] Н. Е. Лукьяленко и Я. В. Пейве, Микровлеиементы в Сельском Хозяйстве Нечернозөмной Полосы СССР, Изд. АН СССР (1954).

[68] Т. Д. Страхов и Т. В. Ярошенко, Тр. Конф. по Микроэльментам, Изд. АН СССР (1952).

[69] Е. Березова и Л. В. Судакова, Химиз. Соц. Землед., 6 (1941).

[70] R. P. Geyer, I. W. Rupel and E. B. Hart, J. Dairy Sci., 28, 291-296 (1945). 